\title{
DIAGNOSTIC ACCURACY OF MAGNETIC RESONANCE IMAGING IN DIAGNOSING BONE TUMORS KEEPING HISTOPATHOLOGICAL CORRELATION AS GOLD STANDARD
}

\author{
Ambreen Farooq, Shahla Zameer, Rehana Khadim*, Anum Manzoor** \\ Pakistan Institute of Medical Sciences (PIMS) Islamabad Pakistan, *Armed Forces Institute of Cardiology (AFIC)/National University of \\ Medical Sciences (NUMS) Rawalpindi Pakistan, **Pak Emirates Military Hospital/National University of Medical Sciences (NUMS) \\ Rawalpindi Pakistan
}

\begin{abstract}
Objective: To determine the diagnostic accuracy of magnetic resonance imaging in diagnosing bone tumors keeping histopathological as correlation gold standard.

Study Design: Descriptive cross-sectional study.

Place and Duration of Study: Departments of Radiology, Orthopedics and Pathology of Pakistan Institute of Medical Sciences, Islamabad, from Jan 2018 to Jan 2019.

Methodology: All the patients who had complain of bone deformity or pain with high suspicion of neoplastic pathology involving bone and soft tissue on radiograph were included in study. Patients were first diagnosed on conventional radiography followed by magnetic resonance imaging. Magnetic resonance imaging with contrast was done on Phillips 1.5 tesla machine. T1W, T2W, STIR images, Fat suppressed, PD spair and post contrast T1W images were obtained. Positive magnetic resonance imaging findings which were noted were; marrow involvement, cortical break, soft tissue involvement, joint involvement, neurovascular bundle involvement and post contrast enhancement on T1W imaging. Then bone biopsy was performed. The removed bone was sent for histopathological examination in all cases. The histopathological reports were collected. The results were entered in structured proformas. Data was collected after the informed consent. All the data was entered and analyzed using SPSS version-23.

Results: Fifty patients of both genders were recruited during our study duration. 32 (64.0\%) were male while 18 $(36.0 \%)$ were female patients. Mean age of the patient was $54.5 \pm 14.3$ years with range 18 to 80 years. Among the benign tumors vertebral hemangiomas were most commonly found $5(10.0 \%)$ followed by osteochondroma which was $4(8.0 \%)$, while among malignant tumors metastatic deposits/secondaries were most commonly found $11(22.0 \%)$, followed by multiple myeloma $6(12.0 \%)$ then Ewing Sarcoma and Osteosarcomas. Study showed sensitivity, specificity and accuracy in differentiating benign from malignant of $94.12 \%, 90 \%$ and $92.59 \%$.

Conclusion: In evaluating bone tumors, magnetic resonance imaging plays an important role. Whenever a bony pathology is detected that cannot be characterized and shows features of aggressive pathology magnetic resonance imaging is indicated. Magnetic resonance imaging is superior in detecting osseous lesions with marrow invasion and soft tissue component. It is helps to locally stage the disease, and by identifying the perilesional invasion and extension it helps the surgeon to plan the surgery. It is also used to assess the response of neoadjuvant therapy followed by restaging. It can further be used for follow up assessment of patient after completion of treatment.
\end{abstract}

Keywords: Bone tumor, Diagnostic accuracy, Gold standard, Histopathology, Magnetic resonance imaging.

This is an Open Access article distributed under the terms of the Creative Commons Attribution License (http://creativecommons.org/licenses/by/4.0), which permits unrestricted use, distribution, and reproduction in any medium, provided the original work is properly cited.

\section{INTRODUCTION}

Bone tumors and tumor like lesions usually require more than one imaging modality, which includes conventional radiography, bone scinti-

Correspondence: Dr Ambreen Farooq, House No. 19A, Sector-A, Suckhchain Avenue, DHA-II, Islamabad Pakistan

Received: 09 Jun 2019; revised received: 03 Oct 2019; accepted: 07 Oct 2019 graphy, CT, MRI and PET. The primary method for evaluating a bone tumors and tumor-like lesions is conventional radiograph. Whenever a bony pathology is detected that cannot be characterized and shows features of aggressive pathology MRI is indicated ${ }^{1}$. The excellent contrast resolution and multiplanar capabilities of MRI has led to much superior evaluation of intra- 
compartmental and extra compartmental extent of bone tumor, particularly with extension of tumor into the perilesional muscles, neurovascular bundle, displacement or invasion of adjacent fat planes, extent of bone marrow involvement, degree of intra-articular extension and presence of intra-tumoral necrosis and haemorrhage ${ }^{2}$. When a definite final diagnosis cannot be reached, MRI helps us to narrow down the differential diagnosis. And this is how it has changed the approach to diagnose bone tumors and bone tumor like lesions from a single modality based diagnosis which initially included conventional radiograph only to multi-modality based diagnosis which now includes MRI as well. Newer 3 Tesla MRI machines are faster with improved SNR (signal to noise ratio), resulting in better spatial and contrast resolution ${ }^{3}$.

Cases with aggressive and indeterminate lesions tend to be confirmed histopathologically for staging and treatment plan. The contaminated biopsy tract needs to be surgically removed 4 . Contrast-enhanced MRI (CEMRI) reveals the most vascularized parts of the tumor and MRI guidance makes it possible to avoid taking biopsy from the necrotic area of the tumor ${ }^{5}$. The most vascularized parts of the cancer can be found in the contrast enhanced MRI (CEMRI) and MRI guidance can help prevent necrotic biopsies 6 . It helps in determining proper size and dimensions of the bony lesion, detecting intramedullary extension, invasion of adjacent physeal plates, joints, muscles, and neurovascular bundles for localized staging of disease process. It helps the orthopedic surgeon in surgically planning. Re-evaluation after neoadjuvant therapy and surgical treatment should also be done by MRI7.

In many cases of musculoskeletal neoplasia, the high contrast resolution of MRI in soft tissue studies has replaced the need for CT scans. MRI is the best way to locally assess the disease process. In areas such as arm, leg and foot, which are poor deficient in fat with limited fat planes, are poorly assessed by $\mathrm{CT}$, where as MR imagery is much better in defining the extent of the soft tissue mass ${ }^{8}$.
MRI is most sensitive and accurate for evaluating changes in bone marrow, it can be helpful in differentiating benign from malignant lesions but it is not always specific as many lesions show variable characteristics on $\mathrm{T} 1$ and $\mathrm{T} 2$ weighted imaging. So characterization of bony lesions can be further improved using MR diffusion-weighted (DW) imaging and apparent diffusion coefficients (ADC). MR DW imaging is sensitive in detecting changes in micro diffusion of water in intra and extra cellular compartment of the lesion. While ADC is dependent on the ratio of extracellular and intracellular components, cell density, intracellular organelles, matrix fibers, and soluble macromolecules ${ }^{9}$. Literature has in-sufficiently explored the role of MRI in predicting malignancy ${ }^{10}$.

This study aims to discuss MRI characteristics to help differentiate the bone tumors and to determine the accuracy of MRIs in the diagnostics of bone tumors with histopathology as gold standard.

\section{METHODOLOGY}

It was a descriptive cross-sectional study carried out at Departments of Radiology, Orthopedics and Pathology of Pakistan Institute of Medical Sciences, Islamabad from January 2018 till January 2019. All the patients who had complain of bone deformity or pain with high suspicion of neoplastic pathology involving bone and soft tissue on radiograph were included in study. Patients were first diagnosed on conventional radiography followed by MRI. MRI with contrast was done on Phillip 1.5 tesla machine. T1W, T2W, STIR images, Fat suppressed, PDspair and post contrast T1W images were obtained.

Positive MRI findings which indicated benign etiology were; 1) Well defined lesion with well circumscribed margins, 2) lobulated in shape, 3) small size, 4) absence of periosteal reaction, 5) absence of neurovascular involvement, 6) absence of soft tissue component and 7) presence of normal fatty marrow.

MRI features that indicated malignant etiology were; 1) Large lesion, 2) showing periosteal 
reaction, 3) cortical destruction, 4) neurovascular involvement, 5) soft tissue component, 6) higher degree of enhancement on T1W post contrast studies and, 7) bone marrow involvement.

All the patients with positive MR findings were then referred to orthopedic surgery department for bone biopsy. The removed bone was sent for histopathological examination. The histopathological reports were collected. The results were entered in structured proformas. Data was collected after the informed consent. All the data was entered and analyzed using SPSS version- 23 .

\section{RESULTS}

Fifty patients of both genders were recruited during our study duration. $32(64.0 \%)$ were male while 18 (36.0\%) were female patients. Mean age of the patient was $54.5 \pm 14.3$ years with range 18 to 80 years. Among the benign tumors vertebral hemangiomas were most commonly found 5 $(10.0 \%)$ followed by osteochodroma which was 4 $(8.0 \%)$, while among malignant tumors metastatic

Table-I: List of specific diagnosis bone tumors and number of cases.

\begin{tabular}{l|c|c|c}
\hline Benign Tumors & $\begin{array}{c}\text { No. of } \\
\text { Cases }\end{array}$ & $\begin{array}{c}\text { Malignant } \\
\text { Tumors }\end{array}$ & $\begin{array}{c}\text { No. of } \\
\text { Cases }\end{array}$ \\
\hline Osteochondroma & 4 & $\begin{array}{c}\text { Multiple } \\
\text { Myeloma }\end{array}$ & 6 \\
\hline Giant Cell Tumor & 4 & $\begin{array}{c}\text { Metastasis } \\
\text { Deposits/ } \\
\text { Secondaries }\end{array}$ & 11 \\
\hline $\begin{array}{l}\text { Aneurysmal Bone } \\
\text { Cyst }\end{array}$ & 2 & Ewing Sarcoma & 5 \\
\hline $\begin{array}{l}\text { Chondromyxoid } \\
\text { Fibroma }\end{array}$ & 1 & $\begin{array}{c}\text { Osteosarcomas } \\
\text { Non-Hodgkin } \\
\text { Lymphoma }\end{array}$ & 1 \\
\hline $\begin{array}{l}\text { Osteoid Osteoma } \\
\text { Osteoblatoma }\end{array}$ & 2 & $\begin{array}{c}\text { Chondrosarco } \\
\text { ma }\end{array}$ & 2 \\
\hline $\begin{array}{l}\text { Vertebral } \\
\text { hemangiomas }\end{array}$ & 5 & $\begin{array}{c}\text { Total no of } \\
\text { malignant } \\
\text { tumors }\end{array}$ & 29 \\
\hline $\begin{array}{l}\text { Total no of } \\
\text { benign tumors }\end{array}$ & 21 & \multicolumn{2}{|c}{} \\
\hline
\end{tabular}

deposits/secondaries were most commonly found $11(22.0 \%)$, followed by multiple myeloma $6(12.0 \%)$ then Ewing Sarcoma and Osteosarco- mas as shown in table-I. Comparisons of benign and malignant tumors are described in table-II.

The association of MRI diagnosis and histopathological diagnosis was carried out by using Chi-square test, which showed statistical significance with $p<0.04$ as shown in table-II. Study sho-

Table-II: Showing comparison of benign and malignant tumors.

\begin{tabular}{l|c|c}
\hline Tumour Characteristics & $\begin{array}{c}\text { Benign } \\
\text { Tumors }\end{array}$ & $\begin{array}{c}\text { Malignant } \\
\text { Tumors }\end{array}$ \\
\hline Size $<5 \mathrm{~cm}$ & 21 & 9 \\
\hline Size $>5 \mathrm{~cm}$ & - & 20 \\
\hline Well-defined & 13 & 3 \\
\hline Lobulated & 8 & 2 \\
\hline Irregularly marginated & & 20 \\
\hline Periosteal Reaction & - & 12 \\
\hline Cortical Breech & 3 & 13 \\
\hline Neurovascular bundle & - & 6 \\
involvement & 2 & 12 \\
\hline Enhancement & 6 & 17 \\
Heterogeneous & - & 4 \\
Homogenous & - & 8 \\
\hline Joint Involvement & 5 & - \\
\hline Soft Tissue Extension & & \\
\hline Presence of fat component & & \\
\hline Table-III: Comparison of & & \\
\hline
\end{tabular}

Table-III: Comparison of diagnosis made on the basis of MR Imaging and histopathological diagnosis.

\begin{tabular}{l|c|c|c}
\hline & $\begin{array}{c}\text { MRI } \\
\text { Diagnosis }\end{array}$ & $\begin{array}{c}\text { Histopathology } \\
\text { Diagnosis }\end{array}$ & $\begin{array}{c}p- \\
\text { value }\end{array}$ \\
\hline $\begin{array}{l}\text { Benign } \\
\text { Cases }\end{array}$ & $16(32 \%)$ & $18(36 \%)$ & 0.04 \\
\hline $\begin{array}{l}\text { Malignant } \\
\text { Cases }\end{array}$ & $34(68 \%)$ & $32(64 \%)$ & 0.45 \\
\hline
\end{tabular}

Table-IV: Shows diagnostic variables of MR imaging.

\begin{tabular}{l|c}
\hline Diagnostic Variables & MRI \\
\hline Sensitivity; TP/(TP+FN) & $94.12 \%$ \\
\hline Specificity; TN/(TN+FP) & $90 \%$ \\
\hline $\begin{array}{l}\text { Positive Predictive Value; } \\
\mathrm{TP} /(\mathrm{TP}+\mathrm{FP})\end{array}$ & 94.12 \\
\hline $\begin{array}{l}\text { Negative Predictive Value; } \\
\text { TN/(TN+FN) }\end{array}$ & $90 \%$ \\
\hline $\begin{array}{l}\text { Diagnostic Accuracy; } \\
(\mathrm{TP}+\mathrm{TN}) / \text { All Patients }\end{array}$ & $92.59 \%$ \\
\hline
\end{tabular}

wed sensitivity, specificity and accuracyin differentiating benign from malignantas $94.12 \%, 90 \%$ and $92.59 \%$. 


\section{DISCUSSION}

Imaging assessment of bone tumors is important as it helps to distinguish between malignant and benign lesions. The distinguishing of multiple myeloma from secondaries requires history and pathological correlation ${ }^{11}$. MRI helps us in describing the lesion andmaking an early diagnosis. In our study of 50 patients, vertebral hemangiomaswere in 5 patients $(14.0 \%)$, which was commonest among benign tumors while amid malignant tumors, metastatic deposits/ secondaries were most commonly found, 11 patients $(22.0 \%)$, followed by multiple myeloma in 10 patients $(20.0 \%)$ and then Ewing Sarcoma and Osteosarcomas through MRI.

Hemangioma is commonest spinal benign bone tumor as seen in our study ${ }^{12}$. MRI can efficiently detect thepresence of lipid tissue or hematopoietic marrow in the areas of even very little trabecular bone. Presence of normal fatty marrow that gives high signal intensity on T1W imaging similar to the subcutaneous fat in the lesion is highly suggestive of a benign etiology as can be seen in hemangioma ${ }^{13}$. Osteochondroma is the second most common benign tumor according to our study. It is part of a growth plate which separates from the parent bone and it continues to grow independently without any epiphyses. The medullary cavity is continuous with the parent bone which is diagnostic. The lesion can be either sessile or pedunculated. It typically arises from the metaphysealregion, projecting away from epiphysis of the parent bone. MRI is very important in demonstration of its cartilaginous cap. It is low to intermediate signal on T1WI and high on $\mathrm{T}_{2} \mathrm{WI}^{5}$. The cartilaginous cap thickness is the best predictor to detect sarcomatous transformation of the tumor ${ }^{14}$.

Multiple myeloma is the second commonest cause of malignant bone tumors according to our study. It is a common blood cancer with skeletal involvement seen in $80-90 \%$ of patients ${ }^{15}$. It can affect any bone, vertebral involvement is seen in $65 \%$ of cases ${ }^{16}$. It typically shows low signal on T1WI, intermediate to high on T2WI, high signa- lon Fat-suppression and with intenseavid post contrast enhancement ${ }^{17}$.

Benign lesions are sharply defined and well demarcated from the perilesional normal tissues. Malignant lesions tend to extensively invasive and destructive involving the neighboring structures with extension into adjacent soft tissue component. It is the highest predictor of malignancy ${ }^{13}$. Malignant lesions tend to cause cortical disruption with intra medullary extension of the parent bone ${ }^{18}$. Our results were also in concord with it. Neurovascularbundle involvement is another very important predictor of malignancy, which can be best assessed on MRI in contrast to CT and conventional angiography. Its best predictor is the lossof perivascular/perineural fat with encasement and associated stenosis, it is best assessed on axial plane using T2 WI, fat suppressed, PDspair and post contrast studies ${ }^{14}$.

Metastatic deposits are the commonest type of malignant bony tumor according to our study. Bony metastatic deposits are the commonest type of among the metastatic deposits (among liver and lung deposits) and they are even far more prevalent than primary bone tumors ${ }^{19,20}$. Our results also showed similar findings. Because of its excellent soft tissue resolution MRI is the modality of choice for assessing invasion of the marrow cavity by the tumor, and its extension into the surrounding structures ${ }^{19}$. It is highly sensitive for detecting metastatic deposits in the skeleton. It can demonstrate an intramedullary metastatic deposit in advance of cortical destruction occurrence even before apathological osteoblastic process can be manifested as a focal accumulation of radiotracer on a bone $\operatorname{scan}^{21,22}$. It is the modality of choice in patients with suspicion of cord compression due to pathological vertebral body fractures where a damaged edematous cord shows an abnormal high signal on T2 and turboshort tau inversion recovery (STIR) weighted image sequences ${ }^{22}$.

Our study showed sensitivity, specificity and accuracy in differentiating benign from malignant of $94.12 \%, 90 \%$ and $92.59 \%$. Study by 
Bhuyan et al, showed sensitivity and specificity in diagnosing bone tumor to be $100 \%$ and $98 \% 23$. However for differentiating benign from malignant, he found specificity of $94.7 \%$. Our results were also in concord with it. Another study by Lange showed higher sensitivity, specificity and accuracyof MRI in comparison to other imaging modalities. MRI sensitivity, specificity and accuracy was $90.5 \%, 80.1 \%$ and $87.1 \%$, while CT showed $75.6 \%, 80.2 \%$ and $81.1 \%$, PET showed $92.3 \%$, $62.2 \%$ and $82.7 \%$, bone scintigraphy $74.1 \%, 62.5 \%$ and $71.4 \%$ and $x$-rays of $33 \%, 96.1 \%$ and $69.5 \%{ }^{24}$.

Our study had a few limitations, time period of the study was short due to which specific limited no of patients data could be collected. Secondly the machine in our department does not have the diffusion weighted imaging (DW) sequences with apparent diffusion coefficient (ADC), which can further improve the characterization of the bony lesion .

\section{ACKNOWLEDGEMENT}

I would like to thank my supervisor Prof Dr Shahla Zameer, for always being there for my guidance. To my fellow authors, for helping me with variable chores. Special thanks to Dr Ramish Riaz, for being an angel and a dear friend, for always being there and helping me out.

\section{CONCLUSION}

In evaluating bone tumors, MRI plays an important role. Whenever a bony pathology is detected that cannot be characterized and shows features of aggressive pathology MRI is indicated. MRI is superior in detecting osseous lesions with marrow invasion and soft tissue component. It is helps to locally stage the disease, and by identifying the perilesional invasion and extension it helps the surgeon to plan the surgery. It is also used to assess the response of neoadjuvant therapy followed by restaging. It can further be used for follow up assessment of patient after completion of treatment.

\section{CONFLICT OF INTEREST}

This study has no conflict of interest to be declared by any author.

\section{REFERENCES}

1. Bestic JM, Wessell DE, Walker EA, Ying-Kou Yung E, Kransdorf JM, ACR Appropriateness Criteria. Primary Bone Tumors. J Am College Radiol 2013; 17(5): s226-38.

2. Baweja S, Arora R, Singh S, Sharma A, Narang P, Ghuman S, et al. Evaluation of bone tumors with magnetic resonance imaging and correlation with surgical and gross pathological findings. Ind J RadiolIm 2008; 16(4): 611-18.

3. Wong S, Steinbach L, Zhao J, Benjamin CS, Link TM. Comparative study of imaging at $3.0 \mathrm{~T}$ versus $1.5 \mathrm{~T}$ of the knee. Skeletal Radiol 2009; 38(8): 761-69.

4. Ribeiro MB, Oliveira CR, Filippi RZ. Estudohistopatológico do trajeto de biópsia de tumoresmusculoesqueléticosmalignos. Acta Ortopédica Brasileira 2009; 17(5): 279-81.

5. Ojala R, Sequeiros RB, Klemola R, Vahala E, Jyrkinen L, Tervonen $\mathrm{O}$. MR-guided bone biopsy: preliminary report of a new guiding method. J Magn Reson Imaging 2002; 15(1): 82-86.

6. Poulsen $\mathrm{MH}$, Petersen $\mathrm{H}$, Hoilund-Carlsen PF, Jakobsen JS, Gerke O, Karstoft J, et al. Spine metastases in prostate cancer: comparison of technetium-99m-MDP whole-body bone scintigraphy, [(18) F]choline positron emission tomography (PET)/ computed tomography (CT) and [(18) F]NaF PET/CT. BJU Int 2014; 114(6): 818-23.

7. Douis H, Jeys L, Grimer R, Vaiyapuri S, Davies AM. Is there a role for diffusion-weighted MRI (DWI) in the diagnosis of central cartilage tumors?. Skeletal Radiol 2015; 44(7): 963-69.

8. Palmedo H, Marx C, Ebert A, Kreft B, Ko Y, Turler A, et al. Whole-body SPECT/CT for bone scintigraphy: diagnostic value and effect on patient management in oncological patients. Eur J Nucl Med Mol Imaging 2014; 41(1): 59-67.

9. Wang T, Wu X, Cui Y, Chu C, Ren G, Li W. Role of apparent diffusion coefficients with diffusion weighted magnetic resonance imaging in differentiating between benign and malignant bone tumors. World J Surg Oncol 2014; 12(1): 365-70.

10. Albano D, Patti C, Lagalla R, Midiri M, Galia M. Whole-body MRI, FDG-PET/CT, and bone marrow biopsy, for the assessment of bone marrow involvement in patients with newly diagnosed lymphoma. J Magn Reson Imaging 2017; 45(4): 1082-89.

11. Bird JM, Owen RG, D'Sa S, Snowden JA, Pratt G, Ashcroft J, et al. Guidelines for the diagnosis and management of multiple myeloma 2011. Br J Haematol 2011; 154(1): 32-75.

12. Patnaik S, Jyotsnarani $Y$, Susarala R. Imaging features of primary tumors of the spine: a pictorial essay. Ind J Radiolo Imag 2016; 26(2): 279-89.

13. Nascimento D, Suchard G, Hatem M, De Abreu A. The role of magnetic resonance imaging in the evaluation of bone tumours and tumour-like lesions. Insights Imag 2014; 5(4): 419-40.

14. Zamagni $\mathrm{E}$, Cavo M. The role of imaging techniques in the management of multiple myeloma. Br J Haematol 2012; 159(5): 499-13.

15. Davies AM, Sundaram M, James SLJ. Imaging of Bone Tumors and Tumor-Like Lesions (Techniques and Applications) Berlin Heidelberg: Springer; 2009 [Internet]. https://www.springer. com/gp/book/9783540779827.

16. Alyas F, James SL, Davies AM, Saifuddin A. The role of MR imaging in the diagnostic characterization of appendicular bone tumours and tumour-like conditions. Eur Radiol 2007; 17(10): 2675-86.

17. Dutoit JC, Vanderkerken MA, Verstraete KL. Value of wholebody MRI and dynamic contrast enhanced MRI in the diagnosis, follow-up and evaluation of disease activity and extent in multiple myeloma. Eur J Radiol 2013; 82(9): 1444-52. 
18. Greenspan A. Orthopedic imaging: a practical approach, 5th edn. Lippincott Williams \& Wilkins 2011 [Internet]. https:// www.amazon.com/Orthopedic-Imaging-Adam-Green-span$\mathrm{MD} / \mathrm{dp} / 1608312879$.

19. Costelloe CM, Rohren EM, Madewell JE, Hamaoka T, Theriault $\mathrm{RL}, \mathrm{Yu} \mathrm{TK}$, et al. Imaging bone metastases in breast cancer: techniques and recommendations for diagnosis. Lancet Oncol 2009; 10(1): 606-14.

20. Bäuerle T, Semmler W. Imaging response to systemic therapy for bone metastases. Eur Radiol 2009; 19(10): 2495-07.

21. Rajarubendra N, Bolton D, Lawrentschuk N. Diagnosis of bone metastases in urological malignancies - an update. Urol 2010; 76(4): 782-90.

22. O'Sullivan GJ, Carty FL, Cronin CG. Imaging of bone metastasis; an update. World J Radiol 2015; 7(8): 202-11.

23. Lange MB, Nielsen ML, Andersen JD, Lilholt HJ, Vyberg M, Petersen L. Diagnostic accuracy of imaging methods for the diagnosis of skeletal malignancies: A retrospective analysis against a pathology-proven reference. Eur J Radiol 2016; 85(1): 61-67.

24. Bhuyan MH, Bhuyan RK. How accurate is MRI in prediction of musculoskeletal tumors - A prospective evaluation. Int J Business Res 2015; 6(12): 942-46. 